\title{
US science academy report calls for 'bipolar' research
}

\section{Arctic and Antarctic scientists are urged to share data, ideas and infrastructure.}

\section{BY JANE QIU IN PALMER, ANTARCTICA}

$\mathrm{T}$ he Arctic and Antarctic share more than frosty temperatures. Both are experiencing rapid environmental change, and provide sensitive bellwethers for the effects of global warming. Yet scientists studying the ends of the Earth are poles apart in more than just geographical terms, which is hampering research and slowing efforts to understand how ecosystems are responding to climate change.

The warning comes from a strategic report commissioned by the Polar Research Board, a subgroup of the US National Academy of Sciences (NAS), which recommends that the community reshape itself to take a 'bipolar' approach, sharing resources and initiating more holistic research projects to identify common patterns of change at both poles. The report, 'Frontiers in understanding climate change and polar ecosystems', is due for release in the coming months. Its authors hope that it will encourage granting bodies such as the US National Science Foundation to promote more integrated polar research.

Both the Arctic and Antarctic are "highly coupled systems" where changes to land, ocean or atmosphere can have enormous effects on the region as a whole, explains John Priscu, an ecologist at Montana State University in Bozeman, who has worked at both poles during the past 25 years, and is a co-chair of the NAS study. Marine ecosystems at both poles depend on the existence of sea ice, but current models cannot accurately predict recent changes in sea-ice cover. Sharing data on Arctic and Antarctic sea-ice decline could highlight common responses to climate change and help to develop better predictive models of its consequences, the report will argue.

In the Arctic, where the rise in air temperature has been almost twice the global average

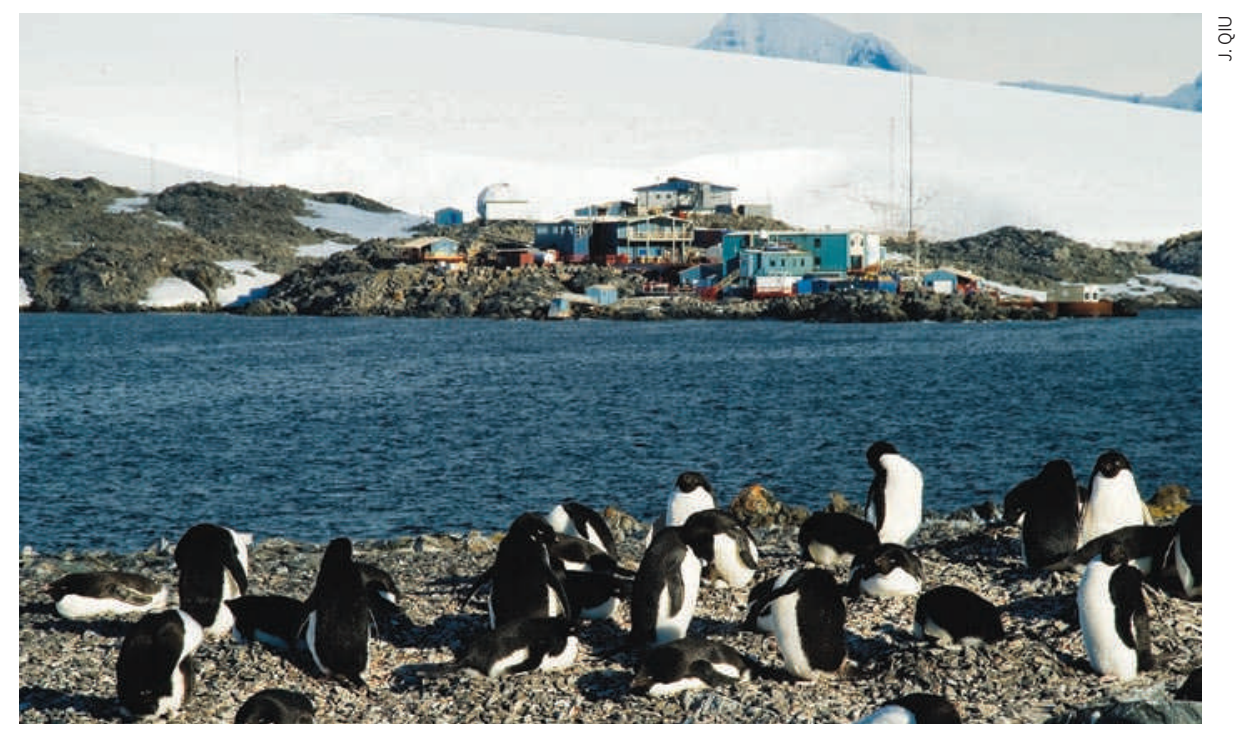

Antarctica's Adélie penguins are shifting further south as warmer temperatures affect the food chain.

over the past few decades (go.nature.com/ xph8q6), permafrost is thawing on a large scale. This is driving changes in vegetation, such as a shift from moss to shrubs, and accelerating carbon release from the ecosystem. In the western Antarctic Peninsula, where mid-winter temperatures have increased by about $6^{\circ} \mathrm{C}$ and the seaice season has shrunk by nearly 90 days during the past 50 years (O. Schofield et al. Science 328, $1520-1523 ; 2010$ ), there are signs that the ecosystem "may be approaching what could be an absolutely catastrophic change", says William Fraser, president of the Polar Oceans Research Group in Sheridan, Montana.

Understanding the tipping points beyond which polar ecosystems would change rapidly and irreversibly is "a gigantic priority", says report co-author Hugh Ducklow, an oceanographer at the Marine Biological Laboratory in Woods Hole, Massachusetts.
Beyond data-sharing, the report urges researchers to take practical steps. To make results from different polar regions more comparable, it says, experimental approaches and measurements of factors such as sea-ice extent or population dynamics should be standardized. Researchers could share expertise about the best way to use infrastructure. They could even pool expensive equipment such as sensors, small submarines, helicopters and icebreakers, shipping it from pole to pole as needed, says Oscar Schofield, an oceanographer at Rutgers University in New Brunswick, New Jersey.

The need for such an approach is urgent, says Fraser. "The ecosystem is being stressed to the point where something has got to give." -

Jane Qiu was in Antarctica as part of the 2010 Marine Biological Laboratory's Logan Science Journalism Fellowship.

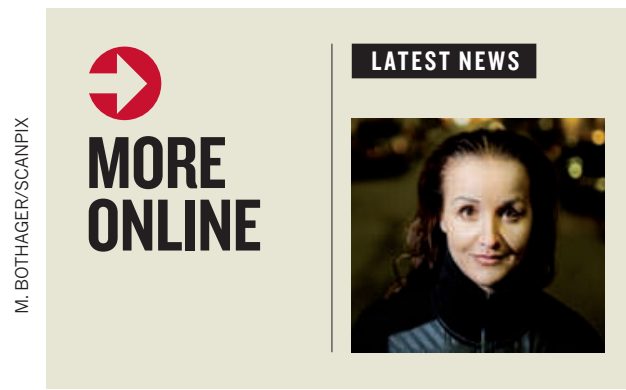

Neuroscientist quits as fraud investigation rocks Danish university go.nature.com/ k1pgir

\section{MORE STORIES}

- Plasma jets key to enduring solar mystery go.nature.com/egqtta - Glassy metal set to rival steel go.nature.com/xgxqtn

- Why dire climate warnings boost scepticism go.nature.com/3yvdja

- Tears are a turn-off go.nature.com/902v6t

\section{VIDEO}

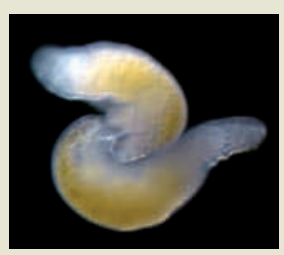

X-rated worm movies reveal sex secrets go.nature. com/8jvjws 